\title{
Investigation of the Thermo-Physical and Mechanical Properties of Coir and Sugarcane Bagasse for Low Temperature Insulation
}

\author{
Mustapha Ndagi, Ajiboye Tajudeen Kolawole, Fabiyi Mustapha Olawale and Abdulkareem \\ Sulaiman
}

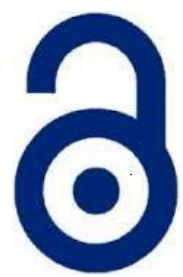

Received: 02 March 2021

Accepted: 29 July 2021

Published: 01 October 2021

Publisher: Deer Hill Publications

(c) 2021 The Author(s)

Creative Commons: CC BY 4.0

\begin{abstract}
This research reports on the suitability of Agricultural bi-products as low temperature thermal insulating materials to replace synthetic insulating materials like polyurethane used in food warmers and ice coolers. Coir and sugarcane bagasse chosen for this research was based on literature review and local availability of materials. Coir was obtained from Badagry, Lagos State and Sugarcane bagasse obtained from Batati, Niger State, the materials were washed, sun dried for three days and cut into smaller pieces before being blended into smaller particles using an electric blender. The blended materials (Coir and Bagasse) were sieved into two different sieve size of $0.5 \mathrm{~mm}$ and $1.0 \mathrm{~mm}$ respectively. The particles sizes were then combined into blend ratios of 50/50, 60/40, and 70/30 using Gum Arabic as binder. Thermal conductivity test showed that $1.0 \mathrm{~mm}$ particle size coir mixed with sugarcane bagasse has the lowest thermal conductivity of $0.01467 \mathrm{~W} / \mathrm{mK}$ whilst that of $0.5 \mathrm{~mm}$ particle size has thermal conductivity of 0.01472 $\mathrm{W} / \mathrm{mK}$ this is lower compared to the measured thermal conductivity of the polyurethane control sample of 0.01832 $\mathrm{W} / \mathrm{mK}$. Sample F $\left(1.0 \mathrm{~mm}\right.$ particle size,70\% coir and 30\% bagasse) with a thermal diffusivity of $5.15 \times 10^{-5} \mathrm{~m}^{2} / \mathrm{s}$, water absorption capacity of $410 \%$, UTS of $0.219 \mathrm{MPa}$, Compressive strength of $0.583 \mathrm{MPa}$, Specific heat capacity of $1141.3 \mathrm{~J} / \mathrm{kgK}$ and thermal resistivity of $68.16 \mathrm{~W} / \mathrm{m} / \mathrm{K}$ is most suitable replacement for polyurethane as low temperature thermal insulator. This is corroborated by the performance evaluation test with carried out between polyurethane lined food warmer and bio-composite lined food warmer. The two test samples have close ice melt rate values and the polyurethane slightly edge the Bio-composite insulating material by $1.2 \%$ in efficiency. The edge in efficiency can be accepted as all materials used in the development of the bio-composite insulating material are completely bio-degradable and environmentally friendly.

Keywords: Bio-degradable, composite, thermal insulation, thermal diffusivity, ultimate tensile strength, water
\end{abstract} absorption capacity.

\section{INTRODUCTION}

Insulation plays a vital role in the general sustainability of life on earth, it has been in existence since the stone ages when early men wore dead animal skin to protect himself from the elements. However, as they advance, they used not only materials that were found in nature, but discovered others which were suitable for insulation. Processed organic materials produced the first insulated panels in the 19th century: meanwhile an increasing range of artificial materials were developed (rock wool, fiberglass, foam glass, hollow bricks, and expanded perlite). Although plastic production was well-known in the 19th century, the first plastic foam was not produced until 1941 [1]. There are varieties of application ranges of insulation including: sound or acoustic insulation which prevents the permeability of sound and absorb it or try to disperse it. Sounds transmit through the air so we can distinguish the different types of voices as well as noise. Sounds also travel as a waves through solid objects of the building specially the concrete bodies, so it should be isolated to prevent the transmission of sound from outside to the inside or from one place to another. Insulation from radiation energy is also important, rays like ultraviolet rays, gamma rays $x$ - rays et c. can be harmful to human body if exposed to for an extended period of time. Paper, lead and Aluminium in varying thicknesses are some of the insulating materials used to shield the body from harmful radiation energy.

Mustapha Ndagi', Ajiboye Tajudeen Kolawole®, Fabiyi Mustapha Olawale ${ }^{2}$ and Abdulkareem Sulaiman ${ }^{1}$ 'Department of Mechanical Engineering, Faculty of Engineering \& Technology

University of llorin, P.M.B. 1515, Ilorin, Nigeria.

2Department of Mechanical Engineering, Faculty of Engineering

University of llorin, P.M.B 1515, llorin, Nigeria

E-mail: engrtkajiboye@yahoo.com

Reference: Ndagi et al. (2021). Investigation of the Thermo-Physical and Mechanical Properties of Coir and Sugarcane Bagasse for Low Temperature Insulation. International Journal of Engineering Materials and Manufacture, 6(4), 340-356. 
Some materials do not allow the flow of electric current, such materials are called "electrical insulators" Such as: wood, plastic and ceramic. Insulations that conserve energy by reducing heat loss or gain, control surface temperatures for personal protection and comfort, facilitate temperature control process and prevent vapour flow and water condensation on cold surfaces are known as thermal insulators."

Thermal insulators are those materials that prevent or reduce various forms of heat transfer (conduction, convection and radiation) [2]. Insulator resists the heat transfer from outside to inside or in opposite direction whether the environment temperature is high or low. There are many advantages of thermal insulation that isolates the insulated body or object from the heat and reduces the energy consumption as well as the costs of air-conditioning operation or refrigeration. The temperature range, within which the term "thermal insulation" applies, is from $-75^{\circ} \mathrm{C}$ to $815^{\circ} \mathrm{C}$. All applications below $-75^{\circ} \mathrm{C}$ are termed "cryogenic", and those above $815^{\circ} \mathrm{C}$ are termed "refractory" [6]. Low temperature thermal insulation ranges from $-75^{\circ} \mathrm{C}$ to $15^{\circ} \mathrm{C}$. Applications include; refrigeration of brine, glycol and cold or chilled water. Medium temperature thermal insulation ranges from $16^{\circ} \mathrm{C}$ to $315^{\circ} \mathrm{C}$. Applications include hot water and steam condensate. High temperature thermal insulation ranges from $316^{\circ} \mathrm{C}$ to $815^{\circ} \mathrm{C}$. Applications include; Turbines, stacks, exhausts, incinerators, boilers. [3]

Thermal insulators used now-a-days are made from synthetic materials such as fiberglass, mineral wool, polyurethane foam, polystyrene, glass wool, rock wool, etc.; these insulations are costly and few of them like glass wool and rock wool are carcinogenic in nature. Fiberglass is carcinogenic and while installing this insulator one might feel itching, redness of skin and breathing issues. Polyurethane foam is highly flammable whose smoke contains carbon monoxide, benzene et c., which is not good for environment as well as humans [4]. There is an urgent need for more environmentally friendly, renewable and biodegradable low temperature thermal insulation, to replace the environmentally hazardous ones used presently, this can be achieved through the use of bio composite materials gotten from natural replenishing sources or agricultural by-products.

Bio-composites insulating materials are suitable for low temperature thermal applications. They are renewable, cheap, completely or partially recyclable, and biodegradable. Plants, such as flax, cotton, hemp, jute, sisal, pineapple, ramie, bamboo, banana, coconut fibre, sugarcane bagasse, kapok, etc., as well as wood, used from time immemorial as a source of lignocellulose fibres, are more and more often applied as the reinforcement of composites. Their availability, renewability, low density, and price as well as satisfactory mechanical properties make them an attractive ecological alternative to glass, polystyrene, polyurethane, carbon and man-made fibres used for the application of low temperature thermal insulation. Renewable fibrous thermal insulation materials from trees, plant or animals have the ability to regenerate itself, it requires less energy for production and biodegrade easily when disposed as waste hence have low environmental impact [5].

A cheap reliable and abundant supply of biodegradable fibrous materials can be obtained as by-products from many commercial agricultural processing industries [6]. Materials such as kapok, coconut and sugarcane fibre, cotton, wheat straw, palm leaves, oil palm fibre and others consist of lignocellulosic fibres which can be used as alternative insulation materials. This research seeks to study the thermal properties of bio composite formed from different combinations of sugarcane bagasse, and coconut coir.

\section{LITERATURE REVIEW}

Researchers have begun to focus attention on natural fibre composites (i.e., bio-composites), which are composed of natural or synthetic resins, reinforced with natural fibres. Natural. Fibers exhibit many advantageous properties; they are a low-density material yielding relatively lightweight composites with high specific properties. These fibres also are of significant cost advantages and ease of processing along with being a highly renewable resource, in turn reducing the dependency on foreign and domestic synthetic materials. Recent advances in the use of natural fibres (e.g. cellulose, jute, hemp, bagasse, straw, switch grass, kenaf, coir and bamboo) in composites have been reviewed by several authors.

In (7) authors used kapok, bagasse and coir to form composites of varying mixture rates and their result shows that kapok had the highest thermal conductivity of $0.0220 \mathrm{w} / \mathrm{mK}$ with density of $0.73 \mathrm{~g} / \mathrm{c} 3$, bagasse had thermal conductivity of $0.0074 \mathrm{w} / \mathrm{mK}$ and a density of $0.7780 .73 \mathrm{~g} / \mathrm{c} 3$, while coir had a thermal conductivity of $0.0109 \mathrm{w} / \mathrm{mk}$ and density of $0.626 \mathrm{~g} / \mathrm{c} 3$.this shows that while kapok had the lowest density it also has the highest thermal conductivity value, bagasse on the other hand had the lowest thermal conductivity but a higher density compared to the coir. The coir had a low thermal conductivity better than the kapok and low density better than the bagasse. After different mixture combinations of three materials their result show that a combination of $50 \%$ kapok and $50 \%$ bagasse gave a lower thermal conductivity of $0.0106 \mathrm{~W} / \mathrm{mK}$ though at a higher density of $0.843 \mathrm{~g} / \mathrm{c}^{3}$. Though the mechanical properties such as tensile strength and compressive strength and physical properties such as water absorption capacity of the samples were not determined, there work shows that bio composite of kapok bagasse and coir is suitable for low temperature insulation application.

In (8) authors studied the Thermal Properties of Composite of Rice Husk, Corncob and Bagasse for Building Thermal Insulation. They prepared samples of varying percentage constituents and determined the thermal conductivity of the samples using P.A Hilton Thermal Conductivity Apparatus. Their results show that a combination of $60 \%$ rice husk, $20 \%$ corncob and $20 \%$ bagasse gave the lowest thermal conductivity of $0.1961 \mathrm{w} / \mathrm{mK}$ and highest thermal resistivity of $5.0094 \mathrm{~W} / \mathrm{m} / \mathrm{K}$ at a density of $656 \mathrm{Kg} / \mathrm{m}^{3}$, they also concluded that there was a steady improvement of thermal properties with the addition of sugarcane bagasse but that after $50 \%$ addition the 
improvement in the thermal properties dropped significantly. Though, in their research work it was clearly stated that resistant to mold growth is one of the key physical properties required for picking replacement insulating materials. However, there were no results shown for the water absorption capacity of the individual samples prepared.

In (9) authors worked on Thermal Properties of Bagasse Fly Ash Reinforced Epoxy Composite. They observed that the incorporation of bagasse fly ash particles results in decrease in the thermal conductivity compared to that of pure Epoxy. A maximum decrease of about $44.25 \%$ in thermal conductivity of epoxy is observed with $50 \%$ wt of bagasse fly ash in the composite there by improves its thermal insulation capability. They also observed that the thermal expansion is greatly influenced with the addition of bagasse fly ash particles. Coefficient of thermal expansion of pure Epoxy is $23.23 \times 108$ at temperature range of around $45-75^{\circ} \mathrm{C}$ and for composite with $50 \%$ fly ash, thermal expansion is $13.21 \times 10-8 /{ }^{\circ} \mathrm{C}$. In practice it shows that with increasing the bagasse ash percentage in epoxy reduces the Thermal expansion. The specific heat capacity of composite with bagasse fly ash particles exhibited higher specific heat carrying capacity than composite without fly ash. For pure epoxy it is around $1.000 \mathrm{~J} / \mathrm{g}^{\circ} \mathrm{C}$ and for epoxy with $50 \%$ weight fraction bagasse ash composite it is observed as $2.713 \mathrm{~J} / \mathrm{g}^{\circ} \mathrm{C}$. Higher fly ash content in composite higher will be the heat carrying capacity of the composite. Finally, they concluded that the thermal diffusivity of pure epoxy is observed as $3.324 \times 10-7 \mathrm{~m} 2 / \mathrm{s}$. Thermal diffusivity decreased with addition of fly ash, thus its ability to store thermal energy will be increased with increase in the bagasse ash percentage.

In (10) authors developed insulation from coconut husk using suitable binders and implemented it on fixed volume wall then carried out heat loss analysis. Their findings showed that; Heat loss calculation done on fixed volume room without insulation will consume over $582.18 \mathrm{~kg}$ of fuel which is equivalent to the mass of coal needed to produce electricity for this space closed volume. After implement insulation made from coconut husk on fixed volume room approximately 30 to $40 \%$ heat loss was reduced which will reduce the energy consumption by up to 20 to $30 \%$. Total $\mathrm{CO}_{2}$ emissions for this closed system was $1385.58 \mathrm{~kg}$ yearly and after implementing coconut husk insulation on room wall it reduces the yearly $\mathrm{CO}_{2}$ emissions. From the experiment, they concluded that using coconut as insulation on residential building is most efficient and economical way for reducing residential electricity consumption and reduction in $\mathrm{CO}_{2}$ emissions to the atmosphere.

In (11) authors developed and characterized sugarcane bagasse fibre and Nano-silica reinforced epoxy hybrid composites. They prepared composite of bagasse and Nano- silica particulates of varying weight ratio. The tensile and flexural values for the samples were obtained and found out that; all the sugarcane short fibre reinforced epoxy composites obtained higher flexural modulus compared to sugarcane fibre particulates reinforced epoxy composites. Among all the sugarcane short fibre composites, $1 \mathrm{wt} \%$ of sugarcane short fibre composite exhibits the highest tensile and flexural properties compared to $2.5 \mathrm{wt} \%, 3.5 \mathrm{wt} \%$ and $5 \mathrm{wt} \%$. Sugarcane fibre particulates reinforced composites were shown to have better performance when the wt.\% of the fibre increase while compared to short fibre reinforced composites. The sugarcane fibre particulates composites fabricated using ultrasonic processor showed improvement in both tensile and flexural properties due to the DE agglomeration of the fibre particulates.

In (2) author used coconut coir to fabricate an ice cooler which he compared with commercially available rubber lined ice cooler and polystyrene lined ice cooler. By employing a comparative method to determine the effectiveness of the zinc-coated metal sheet ice-cooler with coconut fibre insulation in relation to standard commercially available Rubbermaid and polystyrene ice-cooler. He varied the density of the coconut fibre insulation from $50 \mathrm{~kg} / \mathrm{m} 3$ to 95 $\mathrm{kg} / \mathrm{m}^{3}$ for ice-coolers with wall thickness $38 \mathrm{~mm}, 51 \mathrm{~mm}$, and $64 \mathrm{~mm}$, respectively. For each density the melt rate was measured and compared with the Rubbermaid and polystyrene coolers. The laboratory built ice-coolers were approximately the same volume and similar in shape to the commercial ice-coolers. He concluded that; from the melt rate experimental results of the three laboratory built coconut fibre insulated ice coolers the $64 \mathrm{~mm}$ thick $95 \mathrm{~kg} / \mathrm{m} 3$ density ice cooler performed the best. The $51 \mathrm{~mm}$ and $64 \mathrm{~mm}$ thick ice coolers performed consistently better than the Rubbermaid cooler. The $51 \mathrm{~mm}$ and $64 \mathrm{~mm}$ thick ice coolers performance were comparable to that of the polystyrene ice cooler.

In (12) authors varied percentages of coconut coir to latex binder from $0 \%$ to $60 \%$ by weight of the overall sample weight, they carried out mechanical test including tensile and compression, moisture absorption test and heat absorption test on all the prepared samples. Their conclusion was that; the mechanical test, physical test, and actual heat test showed that $30 \%$ of latex content in coconut fibre composite is the best composition for heat insulator applications. Based on heat absorption test, it shows that the specimen can absorb $95 \%$ of the heat, which is better compared to other specimens and the synthetic rubber (actual product). The tensile strength of the specimen is almost the same with other specimens, but it is lower compared to synthetic rubber sample. Although there were some differences for young modulus properties, but the gap is small. Since the heat insulator application did not require high tensile modulus properties, therefore this difference is acceptable. Their research shows that natural fibre composite has very good heat insulating properties and suitable for various applications.

In (13) authors prepared Two sets of composites using un carbonized (UBp) and carbonized (CBp) bagasse particles by varying the bagasse particles from 10 to $50 \mathrm{wt} \%$. The surface morphology and the mechanical properties of the composites were examined they concluded that the uniform distribution of the bagasse particles in the microstructure of the polymer composites is the major factor responsible for the improvement of the mechanical properties. The bagasse particles added to the RLDPE polymer improved its rigidity and the hardness values of the composites. The tensile and bending strengths of the composite increased with increasing percentage of the bagasse 
to a maximum of $20 w t \% U B p$ and $30 w t \% C B p$. The impact energy and fracture toughness decreases with wt $\%$ bagasse particles. The developed composites have the best properties in the ranges of $30 \mathrm{wt} . \%$ bagasse particle additions and for optimum service condition, carbonized bagasse particles addition should not exceed $30 \mathrm{wt} \%$.

In (14) authors compared the thermal properties of coconut coir, polystyrene and polyurethane compressed at different densities, the thermal conductivities of the samples were determined and their results showed that coconut coir with a density of $95 \mathrm{~kg} / \mathrm{m}^{3}$ had a thermal conductivity of $0.03667 \mathrm{~W} / \mathrm{mK}$, polystyrene with a density of 95 $\mathrm{kg} / \mathrm{m}^{3}$ had a thermal conductivity of $0.02445 \mathrm{~W} / \mathrm{mK}$ and polyurethane with density of $95 \mathrm{~kg} / \mathrm{m}^{3}$ had a thermal conductivity of $0.01939 \mathrm{~W} / \mathrm{mK}$. They concluded that polyurethane had the lowest thermal conductivity, the optimized density and thickness of the polyurethane was analysed and the thermal conductivity was found experimentally by Lee Dick's apparatus from all the three materials namely coconut fibre, polystyrene and polyurethane. It is found that polyurethane of density $95 \mathrm{~kg} / \mathrm{m}^{3}$ and thickness of $64 \mathrm{~mm}$ was the best with the least thermal conductivity of $0.01939 \mathrm{~W} / \mathrm{mK}$.

In (15) authors studied the thermal properties of sugar cane fibre, saw dust, banana fibres, ash, charcoal dust, clay and kaolin. They determined the thermal conductivity, thermal diffusivity and specific heat capacity of the selected materials. Their results showed that; The thermal conductivity $\mathrm{W} / \mathrm{mK}$ values obtained ranged from $0.086 \mathrm{~W} / \mathrm{mK}$ to $0.107 \mathrm{~W} / \mathrm{mK}$ for sugarcane fibres, $0.297 \mathrm{~W} / \mathrm{mK}-0.301 \mathrm{~W} / \mathrm{mK}$ for ash, $0.276 \mathrm{~W} / \mathrm{mK}-0.338 \mathrm{~W} / \mathrm{mK}$ for banana fibres, $0.185 \mathrm{~W} / \mathrm{mK}-0.240 \mathrm{~W} / \mathrm{mK}$ for saw dust, $0.466 \mathrm{~W} / \mathrm{mK}-0.554 \mathrm{~W} / \mathrm{mK}$ for kaolin, $0.210 \mathrm{~W} / \mathrm{mK}-0.308 \mathrm{~W} / \mathrm{mK}$ for clay and $0.1840 \mathrm{~W} / \mathrm{mK}-0.219 \mathrm{~W} / \mathrm{mK}$ for charcoal dust. This clearly shows that sugarcane fibre has the lowest thermal conductivity and highest thermal resistivity coupled with a relatively high thermal diffusivity of $5.05 \times \llbracket 10 \rrbracket \wedge(-7)$ $\mathrm{m}^{\wedge} 2 / \mathrm{s}$ and high specific heat capacity of $1,125 \mathrm{~J} / \mathrm{kgK}$ making it suitable as an ideal material for thermal energy storage systems (TES).

In (16) authors studied the thermal properties of different Agricultural by-products, their results showed that agricultural by-products prove to be good thermal insulators. All the reviewed agriculture by-products showed impressive thermal insulation properties as their thermal conductivity is very low as that of artificial insulators, which shows great thermal insulation properties. The highest thermal conductivity is shown by rice husk which is 0.077 $\mathrm{W} / \mathrm{mK}$ and lowest thermal conductivity is shown by sunflower stalk which is $0.0378 \mathrm{~W} / \mathrm{mK}$. The remaining products in increasing order of thermal conductivity are Palm fibre, hemp, banana fibre, bagasse, coconut fibre.

In (17) authors studied utilization of bagasse waste based materials as improvement for thermal insulation of cement brick. They compared the thermal and mechanical properties of banana based bagasse and sugarcane based bagasse using heat flow meter. They treated the Waste bagasse using sodium hydroxide $(\mathrm{NaOH})$ and characterized it using SEM and XRF. They produced two samples with two different dimensions of $50 \mathrm{~mm} \times 50 \mathrm{~mm} \times 50 \mathrm{~mm}$ and 215 $\mathrm{mm} \times 102.5 \mathrm{~mm} \times 6 \mathrm{~mm}$ for thermal conductivity test. They tested the compressive strength for 7, 14 and 28 days of water curing. Their results showed that banana bagasse has lower thermal conductivity compared to sugarcane bagasse used, with compressive strength of $15.6 \mathrm{MPa}$ with thermal conductivity $0.6 \mathrm{~W} / \mathrm{mK}$.

\section{MATERIALS AND MATERIALS PREPARATION}

Materials used for this research were sugarcane bagasse obtained from Batati, Niger State and coconut fibre (coir) obtained from Badagry, Lagos State. The binder chosen was Gum Arabic manufactured by Nike chemicals India. The Gum Arabic was obtained in a chemical retail store in llorin. In addition, polyurethane insulation sample was obtained from a cold room in Bida Niger State to serve as control sample.

\subsection{Sugarcane Bagasse}

Sugar cane bagasse was obtained from a dump site in Batati Village, Niger State, the obtained bagasse (Figure 1) was washed with water and sun dried for 3 days. The dried bagasse was blended using an electrical blender after which the bagasse was sieved (Figure 2) (using mechanical shaker to obtain $0.5 \mathrm{~mm}$ and $1.0 \mathrm{~mm}$ sieve sizes.

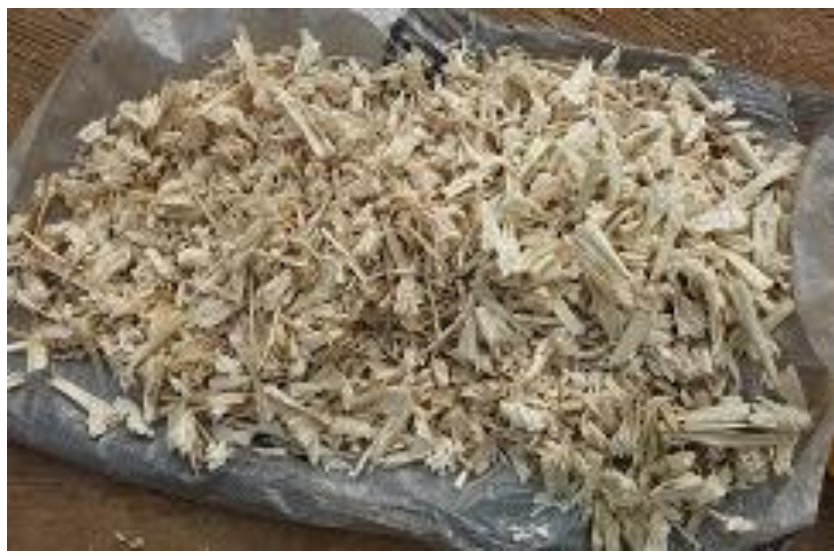

Figure 1: Sugarcane Bagasse washed and dried 


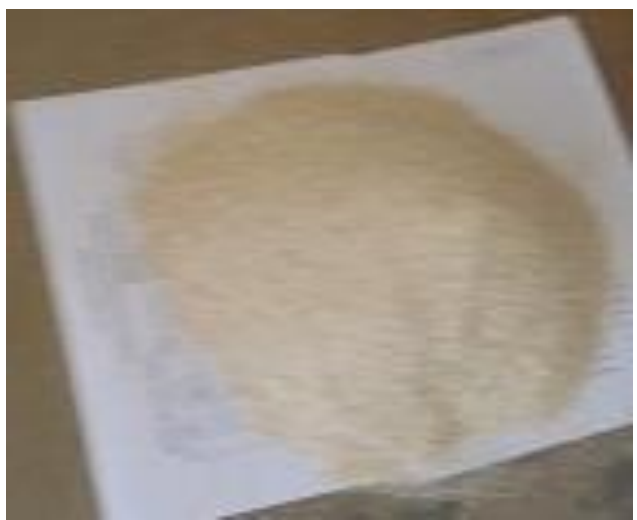

(A)

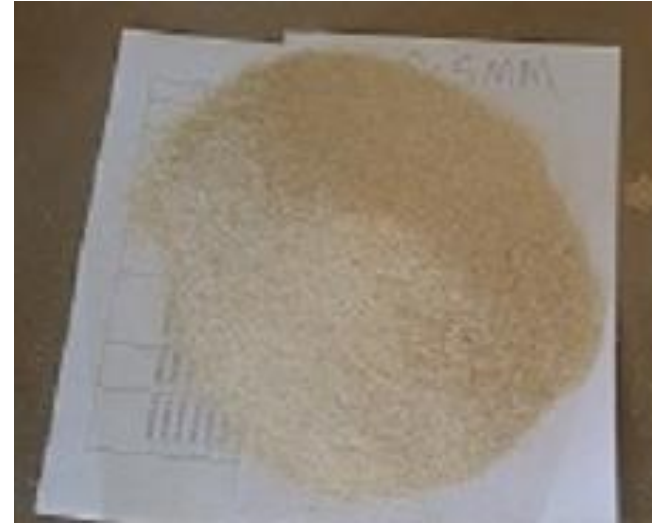

(B)

Figure 2: Bagasse sieved into (A) $0.5 \mathrm{~mm}$ and (B) $1.0 \mathrm{~mm}$ Sieve size

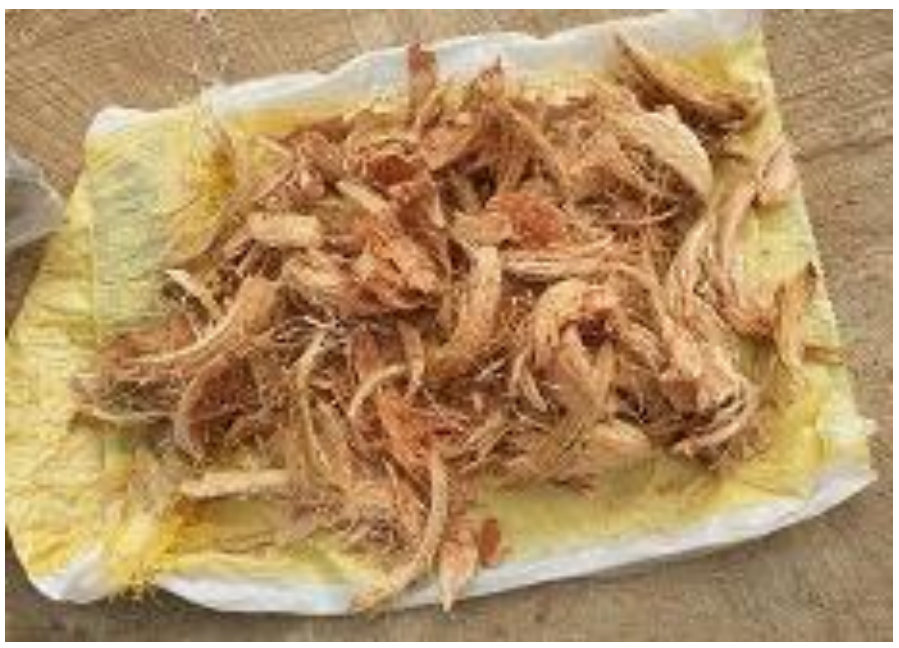

Figure 3: coir washed and dried

\subsection{Coir}

Coconut outer shell was obtained from Badagry in Lagos state. Coir was obtained from the left over of the coconut endocarp. The coir (Figure 3) was removed from the outer shell using knife and plier. Further processing of the coir is same as that of sugarcane bagasse to obtain different size constituents.

\subsection{Sample Mix}

Coir and bagasse were weighed using an electronic weigh balance (HX-T) with $300 \mathrm{~g}$ maximum capacity and sensitivity of $0.01 \mathrm{~g} .5 \mathrm{~g}$ of coir was mixed with $5 \mathrm{~g}$ of bagasse, to give a total of $10 \mathrm{~g}$ for each sieve size (Table 1). 50 $\%$ of the total sample weight which equals $5 \mathrm{~g}$ of gum Arabic was dissolved in $50 \mathrm{~g}$ of water and mixed thoroughly before it was poured into various test mould to make three samples each per sieve size. This process was repeated while varying the (coir/bagasse) constituent with ratios 50/50, 60/40 and 70/30 respectively, for $0.5 \mathrm{~mm}$ and 1.0 $\mathrm{mm}$ sieve sizes making a total of 18 samples per test. The mould was placed on a Testometric universal testing machine (FS 50AT) (Figure 4 A\&B) where a static load of $180 \mathrm{~N}$ was applied for five minutes, after which they were removed and weighed using the electronic weigh balance. Samples were cured in an oven at $105{ }^{\circ} \mathrm{C}$ for 9 hours, the samples were then weighed again to determine their dry weight [16]

\section{EXPERIMENTAL TESTS}

\subsection{Tensile Test}

The tensile strength of the samples was determined in accordance with ASTM standard D- 30392014 Samples were prepared in dumbbell shape (Figure 6) with dimensions of $200 \mathrm{~mm} \times 10 \mathrm{~mm} \times 20 \mathrm{~mm}$ (Figure 7 A). The test was carried out using the $50 \mathrm{kN}$ Testometric universal testing machine FS 50 AT in metallurgy laboratory, department of mechanical engineering, University of llorin. Mounting of the samples one at a time was carried out based on their respective sieve sizes and test speed of $2 \mathrm{~mm} / \mathrm{min}$ was applied until samples failed (Figure $7 \mathrm{~B}$ ). The test was repeated for the various sieve size and constituent ratios. The ultimate tensile strength (UTS) were recorded for each size constituent and ratios. 


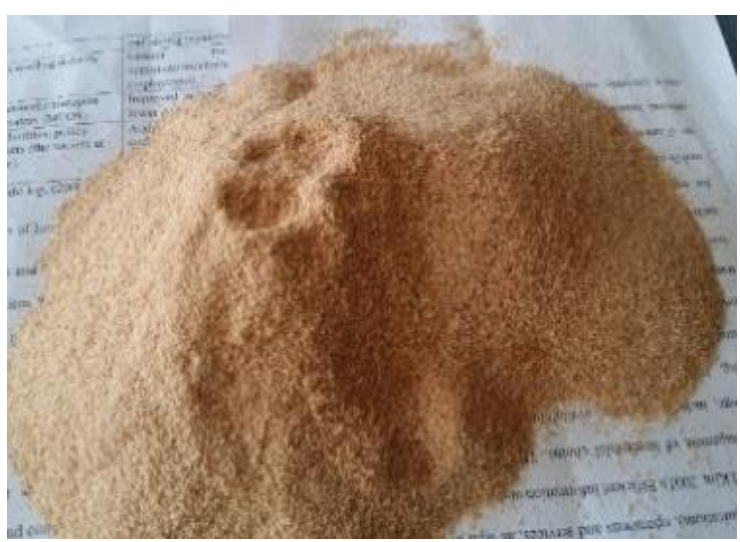

(A)

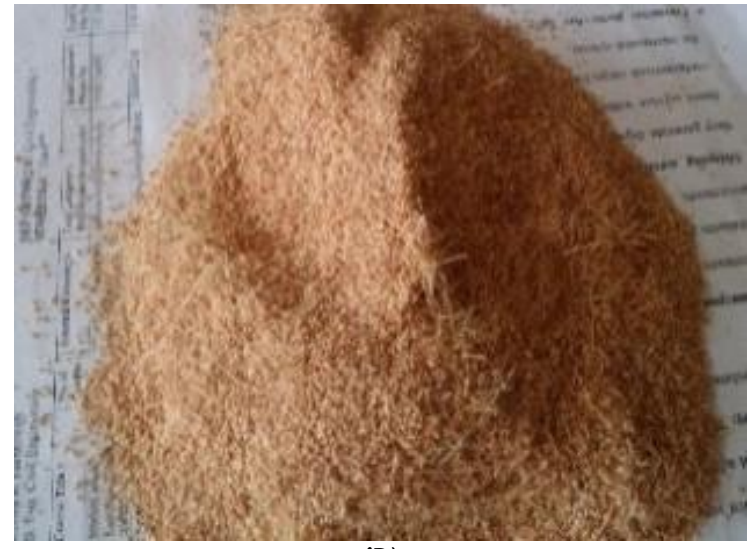

(B)

Figure 4: coir sieved into (A) $0.5 \mathrm{~mm}$ and (B) $1.0 \mathrm{~mm}$ sieve sizes

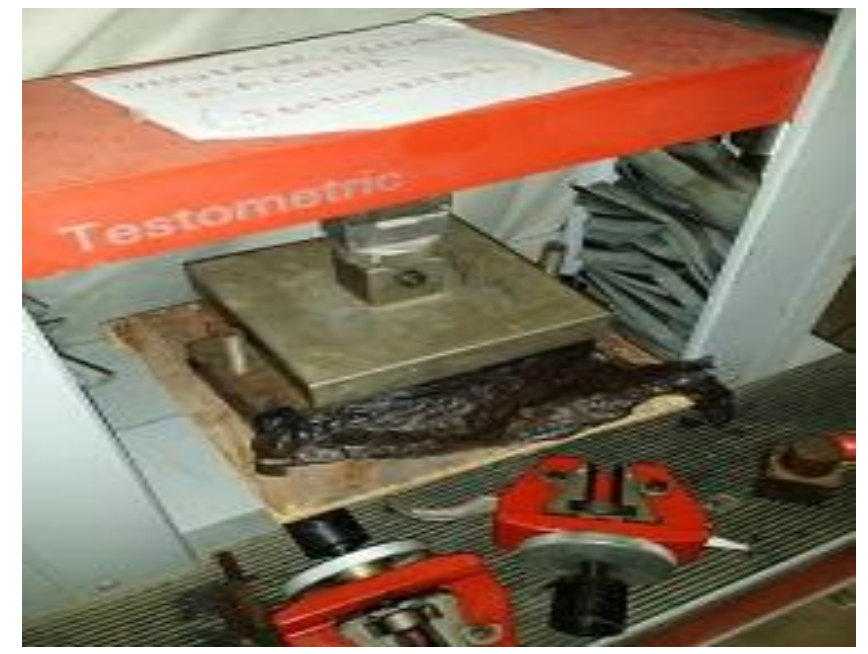

Figure 5: Samples under load during molding

Table 1: Sample mix

\begin{tabular}{llll}
\hline SIEVE SIZE & SAMPLE & COIR & BACASSE \\
\hline \multirow{3}{*}{$0.5 \mathrm{~mm}$} & A & $50 \%$ & $50 \%$ \\
& B & $60 \%$ & $40 \%$ \\
& C & $70 \%$ & $30 \%$ \\
\hline \multirow{2}{*}{$1.0 \mathrm{~mm}$} & D & $50 \%$ & $50 \%$ \\
& E & $60 \%$ & $40 \%$ \\
& F & $70 \%$ & $30 \%$ \\
\hline
\end{tabular}

\subsection{Compressive Test}

The compressive test was determined using a mould of $60 \mathrm{~mm}$ diameter in accordance with ASTM standard D- 3039 2014. $60 \mathrm{~mm} \times 20 \mathrm{~mm}$ (Figure $8 \mathrm{~A}$ ) samples were prepared for different size constituents and mix ratio the compressive strength test was carried out using the $50 \mathrm{kN}$ Testometric universal testing machine FS 50 AT. Samples were mounted one at time based on their respective sieve sizes and test speed of $2 \mathrm{~mm} / \mathrm{min}$ was applied until samples failed (Figure $8 \mathrm{~B}$ ). The test was repeated for the various sieve size and constituent ratios.

\subsection{Thermal Conductivity Test}

Thermal conductivity $(\mathrm{K})$ of a material is a measurement of the material's effectiveness in conducting heat [7]. The inverse of thermal conductivity is thermal resistivity as such a material with low thermal conductivity will have a high thermal resistivity. Thermal conductivity test was determined according to ASTM E 192.112015 using the Armfiled 
Computer Compatible Linear Heat Conduction Accessory (Figure 9) located in landmark university Omu Aran. Samples were prepared with the following dimensions; $35 \mathrm{~mm}$ diameter by $5 \mathrm{~mm}$ thickness (Figure 10) were prepared for the two size sizes and 6 composition ratios respectively. The temperature difference between the hot and cold thermocouples, cross sectional area and temperature difference DT for each composition were recorded this values were used to determine the thermal conductivity in W/MK of each composition.

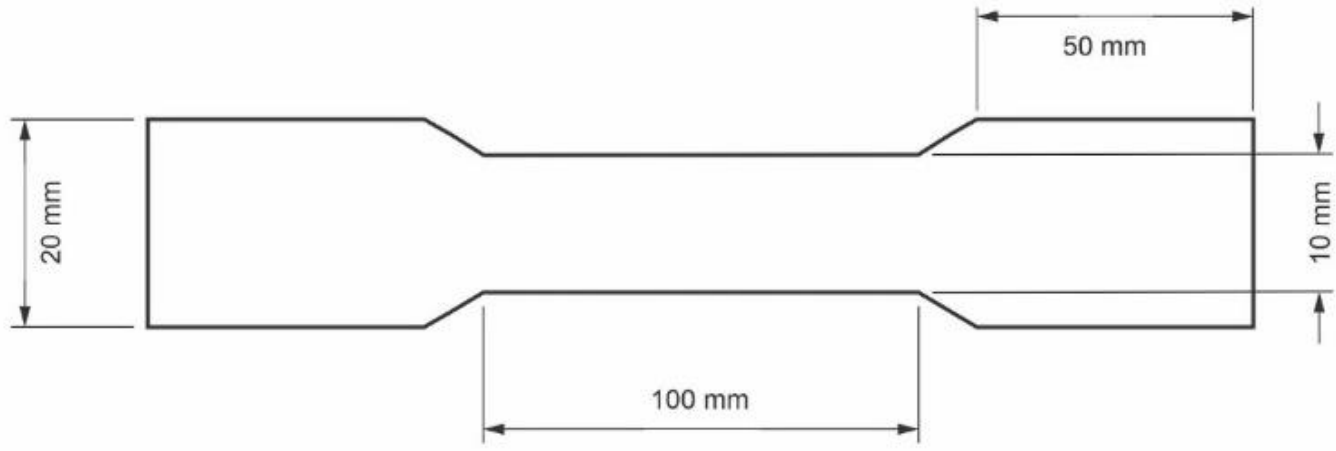

Figure 6: Schematic diagram of tensile test sample

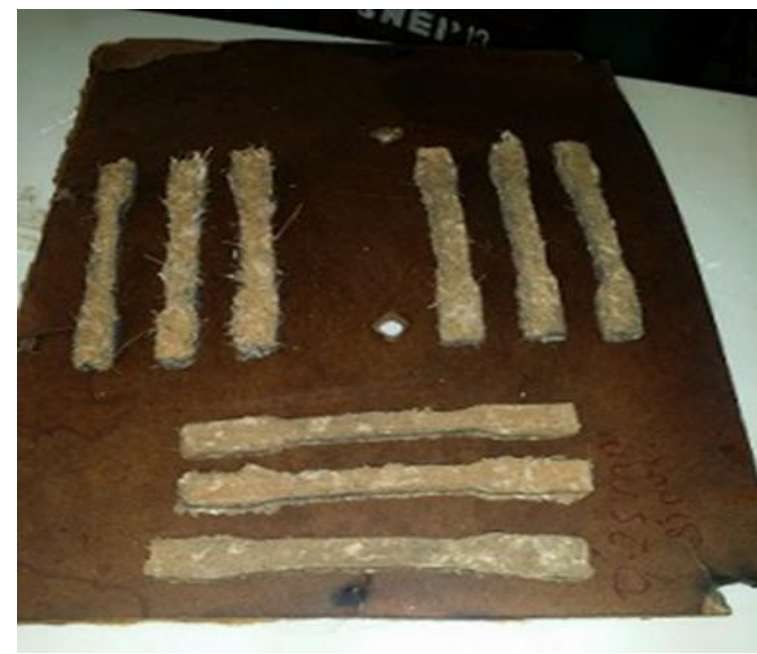

(A)

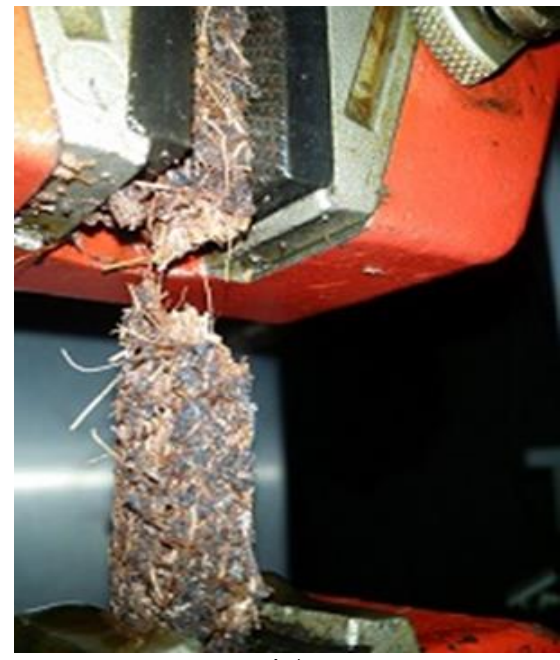

(B)

Figure 7: (A) Prepared tensile samples and (B) sample under test

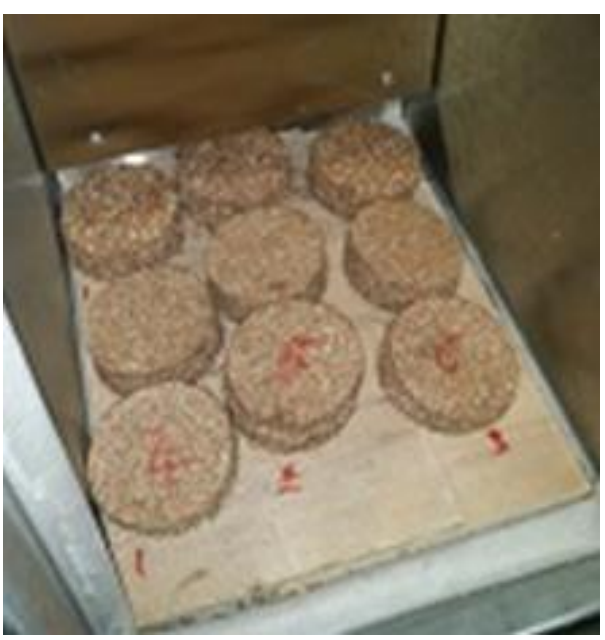

(A)

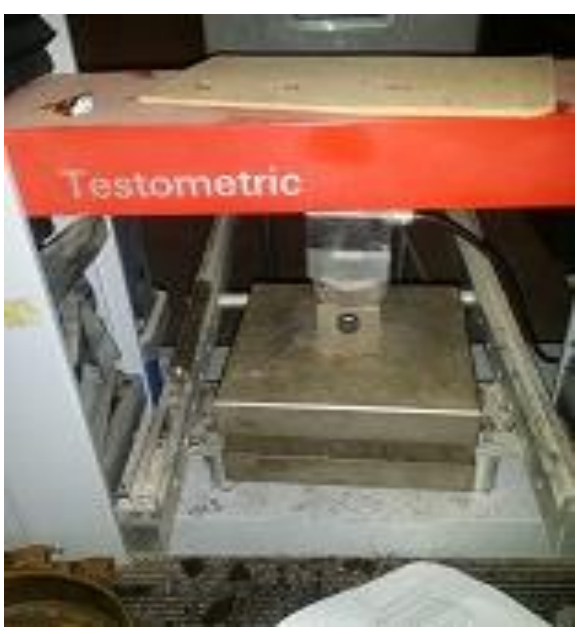

(B)

Figure 8: (A) Prepared compressive test samples and (B) samples under test 


\subsection{Heat Capacity Test}

The heat capacity of material is the ability of the material to store heat [11]. The thermal conductivity of a material is directly proportional to the heat carrying capacity and density of the material. This implies that as the thermal conductivity increases so does the heat carrying capacity of the material. The specific heat capacity of each composition was calculated from the heat capacity which was determined according to ASTM E 192.11 2015, using Mettler Toledo Differential, Sequential calorimetry (DSC) apparatus (Figure 11) located in CSMRD laboratory Kaduna Polytechnic. Samples were prepared in batches of $1.8 \mathrm{mg}$ weight (Figure 12) for all the 6 composition ratios in accordance with the specification of the machine. Samples were tested for a total time frame of 9 minutes and their individual temperature difference recorded. The heat capacity in milli watts $(\mathrm{mW})$ and specific heat capacity in $\mathrm{J} / \mathrm{kgK}$ were then recorded.

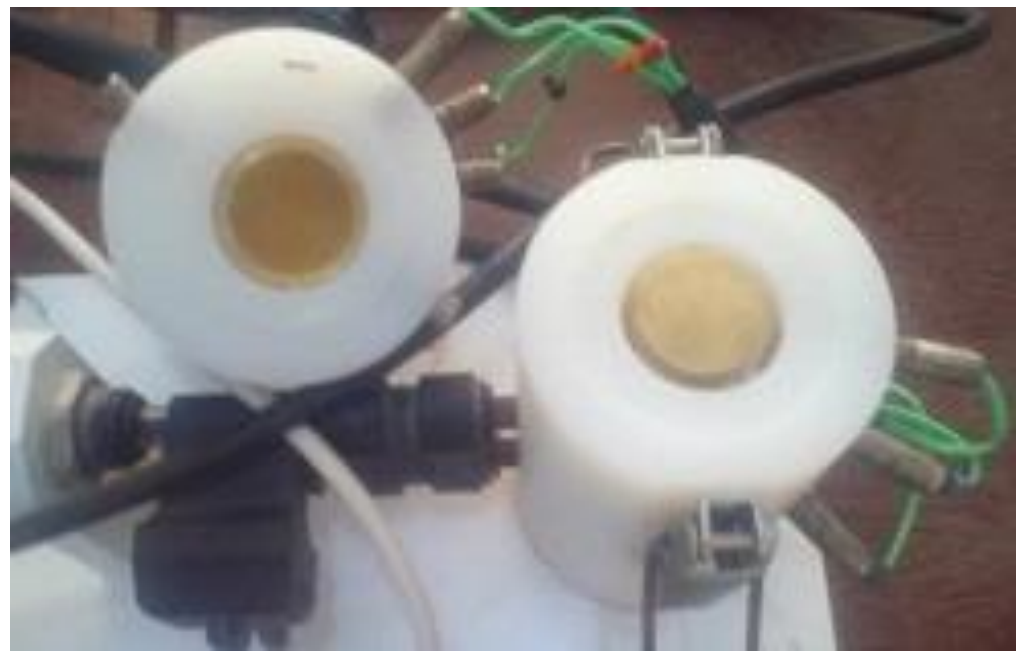

Figure 9: Thermal Conductivity Apparatus

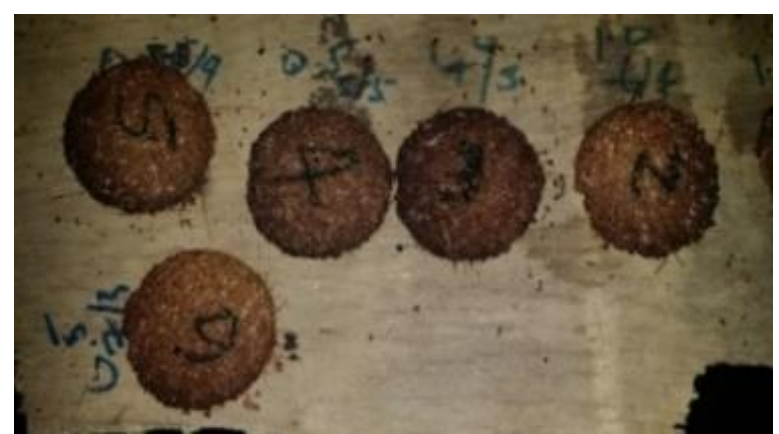

Figure 10: Thermal Conductivity Samples

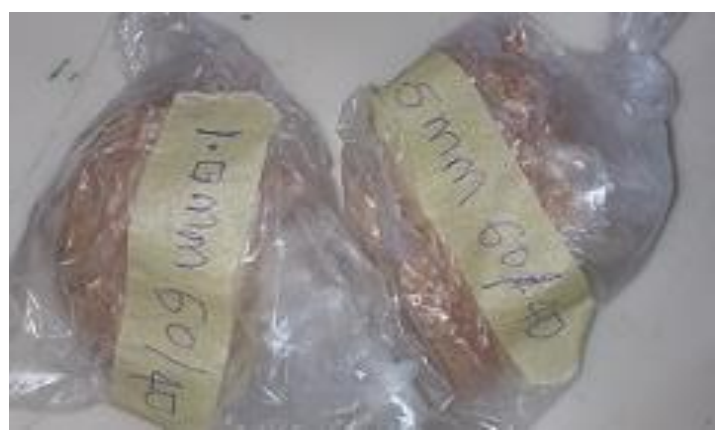

Figure 11: Prepared DSC samples

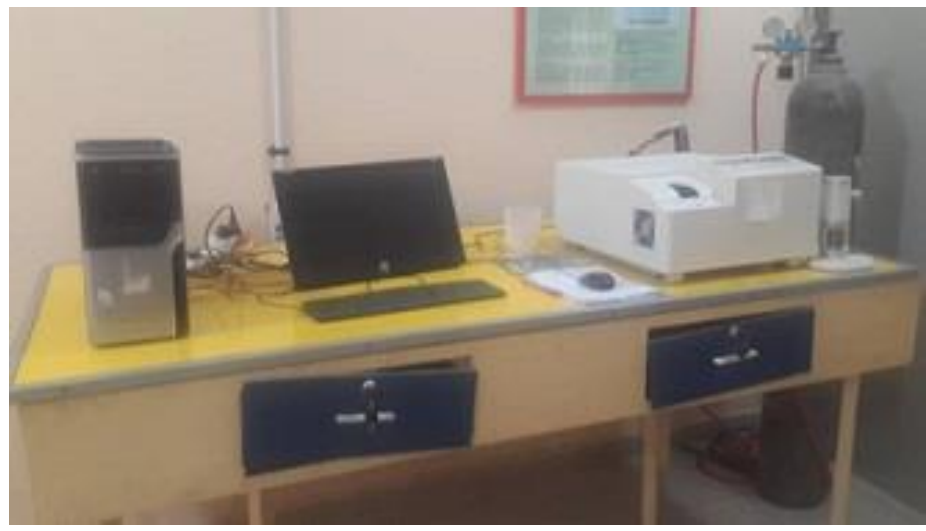

Figure 12: DSC Apparatus 


\subsection{Water Absorption Capacity Test}

The presence of water or humid air in the insulator reduces the thermal insulation value of the material and it may destruct the material rapidly [11]. The moisture is measured by the effect of moisture absorption and permeability. Water absorption capacity was carried out in accordance with ASTM D570-98(2018) $50 \mathrm{~mm}$ diameter $\times 10 \mathrm{~mm}$ thick samples (Figure 13) were prepared and allowed to completely dry for 24 hours after which they were weighed and completely immersed in water for 24 hours (Figure 14). At the end of the 24 hours, samples were removed and a blotting paper used to remove excess water from the surface of the samples before they were weighed again to determine their green weight. The water absorption capacity of individual samples was calculated by subtracting the dry weight from the wet weight and dividing the answer by the dry weight.

$$
\frac{W w-W d}{W d} \times 100=W A C
$$

\subsection{Performance Evaluation Test}

The performance evaluation of bio-composite filled food warmer was carried out by obtaining two sets of identical coolers of different colour, size and manufacturer (Regency and Thermolineo) as shown in (Figure 15) from (Oja Oba market in llorin kwara state). A preliminary test was carried out to ensure that the two sets of coolers operated on the same level of efficiency. One each, from the two set of the coolers was carefully opened to expose the polyurethane insulation inside. The polyurethane was completely removed to leave the internal plastic bare after which it was filled with the bio-composite insulating material (Figure 16). The Bio-composite filled ice cooler was oven dried at $110{ }^{\circ} \mathrm{C}$ for 9 hours after which the inner plastic container was carefully inserted back to cover the insulating the material. Two identical stainless steel moulds were filled with water and (allowed to completely freeze after which the ice were weighed and inserted individually into the four separate coolers, marked 1 (control) and 2 (bio- composite). The lids of the two sets of coolers were firmly closed and the weight of the frozen block was taken at interval of 10 minutes. A total of five readings were obtained for the control coolers and the coir and bagasse filled coolers

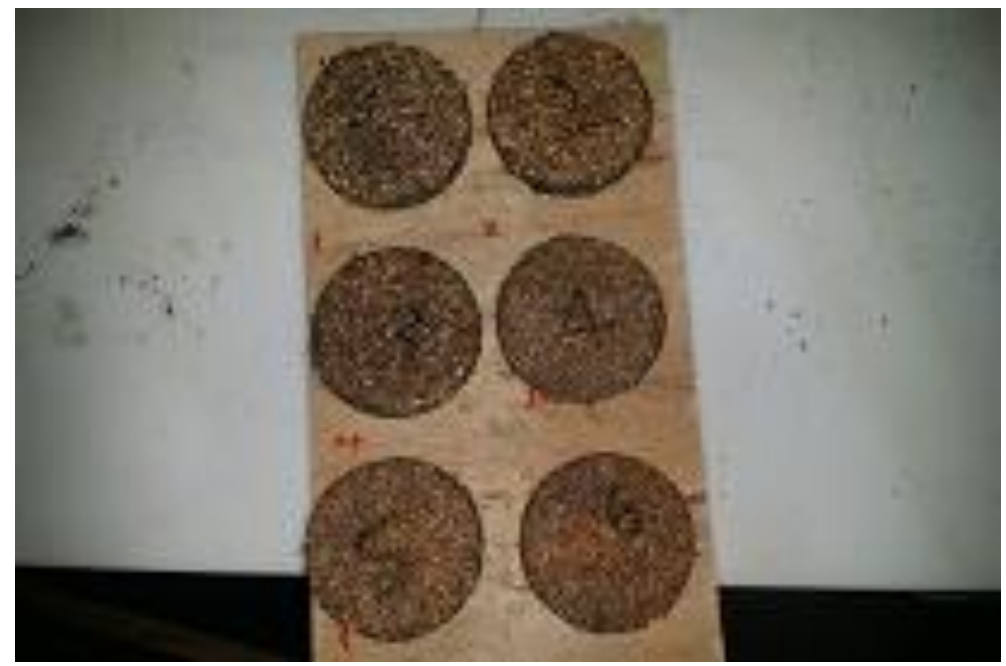

Figure 13: Water absorption capacity sample

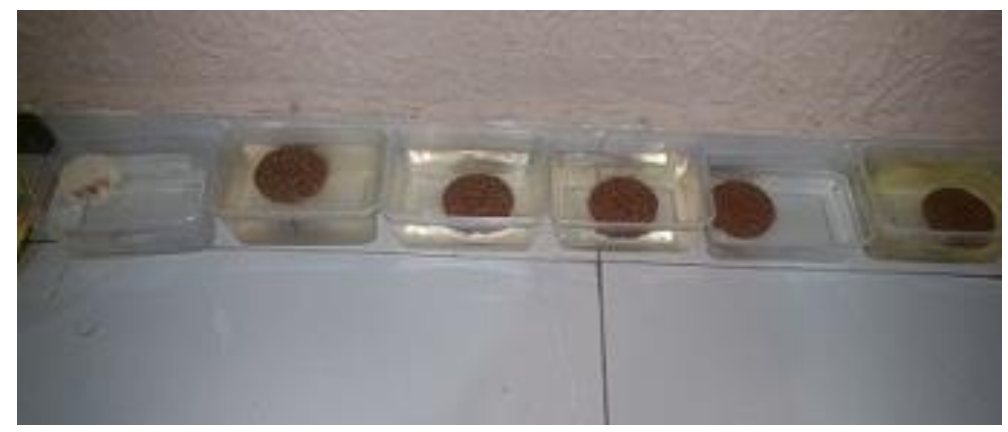

Figure 14: Samples under water absorption test. 


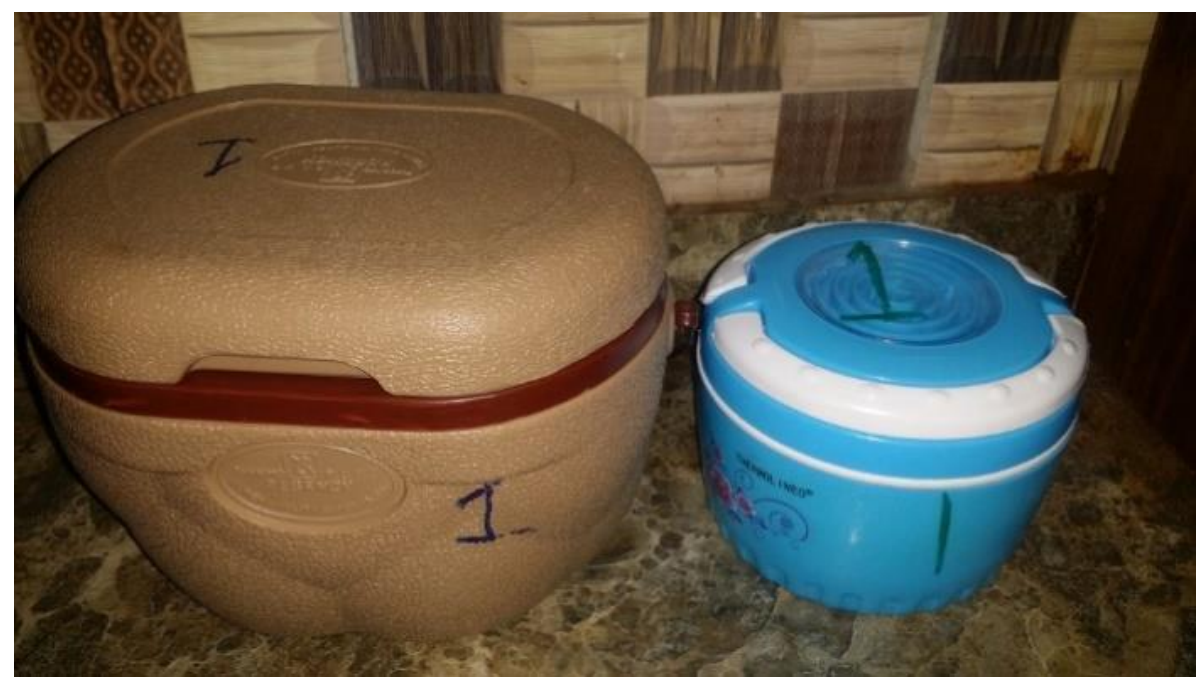

Figure 15: Coolers to serve as control

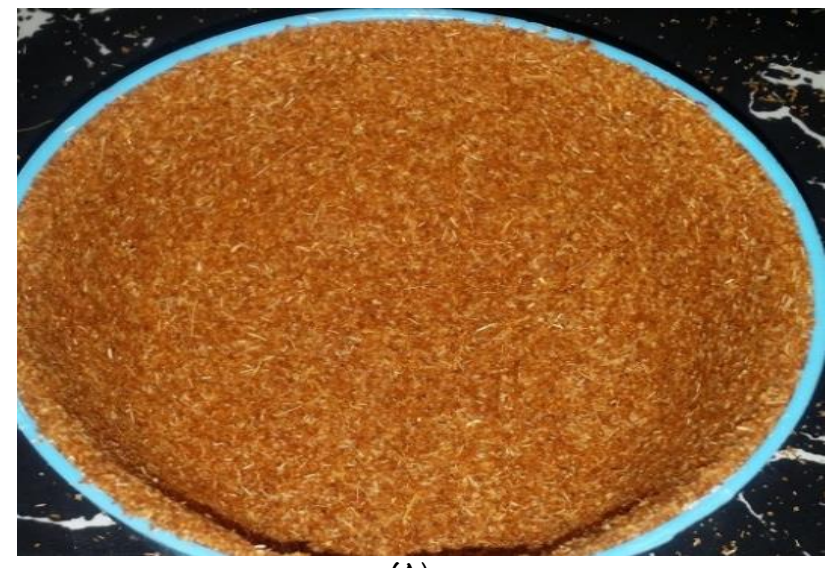

(A)

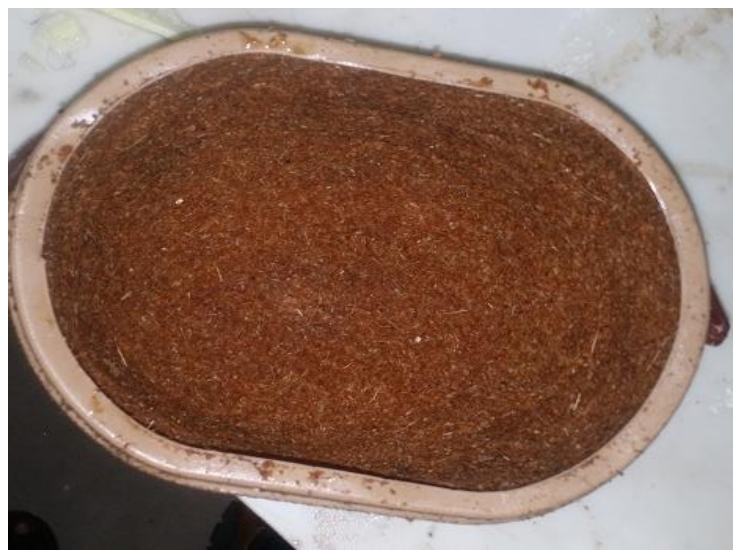

(B)

Figure 16: (A) Regency cooler filled with coir and bagasse and (B) Thermolineo cooler filled with coir and bagasse.

\section{RESULTS AND DISCUSSIONS \\ 5.1 Thermal Diffusivity}

Thermal diffusivity results calculated are presented in Figures 17 and 18 . The results showed that Samples A, B and C (Figure 17) have lower thermal diffusivity of $9.14 \times 10^{-5}, 8.5 \times 10^{-5}$ and $8.1 \times 10^{-5} \mathrm{~m}^{2} / \mathrm{s}$ respectively as compared with the control sample with a diffusivity value of $19.22 \times 10^{-5} \mathrm{~m}^{2} / \mathrm{s}$. A decrease in the thermal diffusivity at sample $B$ was noticed and further decease in thermal diffusivity was noticed at sample $C$. this is mainly due to the increase in coir content from sample $A$ to $C$ which increased the density of the samples thereby reducing the corresponding thermal diffusivity. Similarly, samples D, E and F (Figure 18) also recorded lower thermal diffusivity values compared with the control sample with sample $F$ recording the lowest thermal diffusivity value of $5.1510^{-5} \mathrm{~m}^{2} / \mathrm{s}$ for $1.0 \mathrm{~mm}$ sieve size, sample $F$ has the highest specific heat capacity of $1141.3 \mathrm{~J} / \mathrm{kgK}$ and expectantly it has the lowest thermal diffusivity of $5.15 \times 10^{-5} \mathrm{~m}^{2} / \mathrm{s}$. Sample $\mathrm{F}$ has the lowest thermal diffusivity of the six samples tested with sieve size playing an important role as the larger sieve size gave a larger surface area for heat absorption leading to higher specific heat capacity values. 


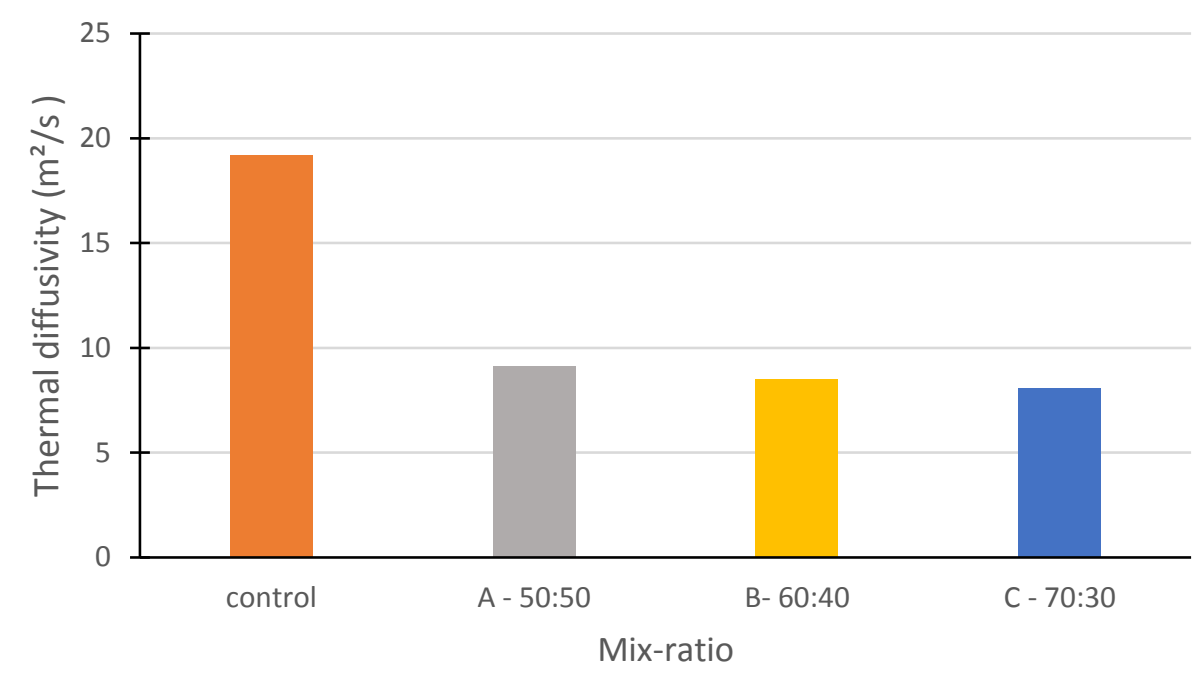

Figure 17: Thermal diffusivity against $0.5 \mathrm{~mm}$ particle size at different Coir:Bagasse mix-ratio

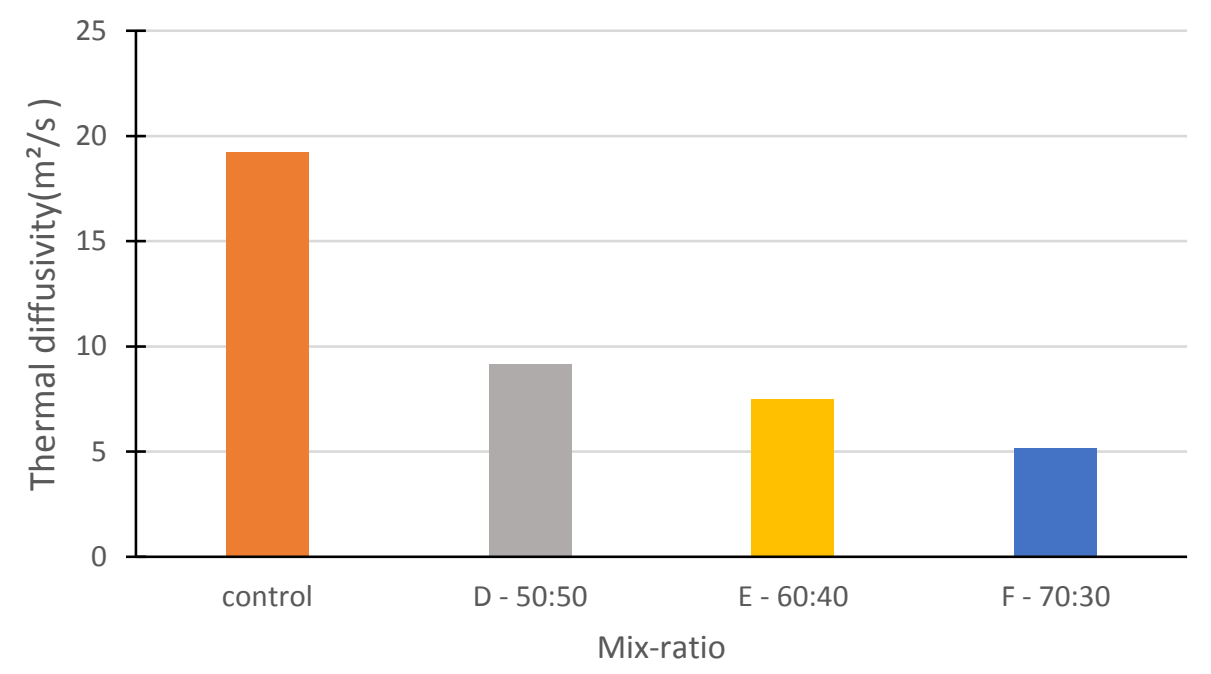

Figure 18: Thermal diffusivity against $1.0 \mathrm{~mm}$ particle size at different Coir:Bagasse mix-ratio

\subsection{Thermal Conductivity}

The thermal conductivity results obtained are shown in Table 2. It shows the relationship between the obtained thermal conductivity of the different constituent ratios and density. Samples A, B and C had the same thermal conductivity of $0.01472 \mathrm{~W} / \mathrm{mK}$ which is lower than the thermal conductivity of the control sample while samples $D$, $\mathrm{E}$ and $\mathrm{F}$ had thermal conductivities of $0.01467 \mathrm{~W} / \mathrm{mK}$ also lower than that of the control sample. The samples exhibited the same thermal conductivity at $0.5 \mathrm{~mm}$ particle size and at $1.0 \mathrm{~mm}$ particle size because the material used are the same regardless of the constituent ratio but the difference in their respective thermal conductivities across the two sieve size constituents, i.e, $0.5 \mathrm{~mm}$ and $1.0 \mathrm{~mm}$, respectively can be attributed to the difference in sieve size. Samples A, B and C are $0.5 \mathrm{~mm}$ sieve size while samples D, E and F are $1.0 \mathrm{~mm}$ sieve size making samples A, B and $C$ denser as a result of smaller particle size which facilitates faster transfer of heat through conduction since the particles are more closely packed together leaving less room for voids and air compared to samples $D, E$ and $F$ which are 1.0 $\mathrm{mm}$ sieve size with bigger particles with more voids and room for air leading to lower conduction of heat. 
Table 2: thermal conductivity and density

\begin{tabular}{|c|c|c|c|c|}
\hline Sample & Ratio & Sieve size $(\mathrm{mm})$ & Thermal conductivity $(\mathrm{W} / \mathrm{m} / \mathrm{K})$ & Density $\left(\mathrm{g} / \mathrm{cm}^{3}\right)$ \\
\hline Control & $100 \%$ Polyurethane & & 0.01832 & 0.1670 \\
\hline A & $50: 50$ & 0.5 & 0.01472 & 0.2474 \\
\hline B & $60: 40$ & & 0.01472 & 0.2765 \\
\hline C & $70: 30$ & & 0.01472 & 0.2599 \\
\hline D & $50: 50$ & & 0.01467 & 0.2453 \\
\hline E & $60: 40$ & 1.0 & 0.01467 & 0.2515 \\
\hline F & $70: 30$ & & 0.01467 & 0.2494 \\
\hline
\end{tabular}

\subsection{Thermal Resistivity}

The thermal resistivity of the samples can be inferred from the value of the thermal conductivity, since thermal resistivity is defined as the inverse of thermal conductivity. It can be expressed mathematically as:

$$
\text { Resistivity }=\frac{1}{K}
$$

From equation 4.1 the thermal resistivity of $0.5 \mathrm{~mm}$ particle size is given by $\frac{1}{0.01472}=67.93 \mathrm{~W} / \mathrm{m} / \mathrm{K}$ and that of $1.0 \mathrm{~mm}$ particle size is given by; $\frac{1}{0.01467}=68.16 \mathrm{~W} / \mathrm{m} / \mathrm{K}$

Therefore, the thermal resistivity of samples $A, B$ and $C$ is $67.93 \mathrm{~W} / \mathrm{k} / \mathrm{K}$ while samples $\mathrm{D}, \mathrm{E}$ and $\mathrm{F}$ have thermal resistivity of $68.16 \mathrm{~W} / \mathrm{m} / \mathrm{K}$.

\subsection{Water Absorption Capacity}

The results of water absorption capacity test for $0.5 \mathrm{~mm}$ and $1.0 \mathrm{~mm}$ sieve size are shown in Figures (19 and 20). From (Figure 19), sample $C$ had the lowest water absorption capacity followed by sample $B$ and sample $A$, the results showed that sample $C$ absorbed $393 \%$ of its initial dry weight as water which is high compared to the measured water absorption capacity of the control sample ( polyurethane) (126\%) samples D, E and F (Figure 20) did not also fair better in the water absorption test, with sample $F$ having the lowest water absorption capacity of $410 \%$ in the $1.0 \mathrm{~mm}$ particle size category which is still higher than the absorption capacity of the control sample. Sample D had the highest water absorption capacity of $449 \%$. The high water absorption capacity of all the samples can be attributed to the hydrophilic nature of coir and sugarcane bagasse which are the main constituents of the biocomposite material. Also the binder being water soluble contributed to the high water absorption capacity of the bio-composite materials used.

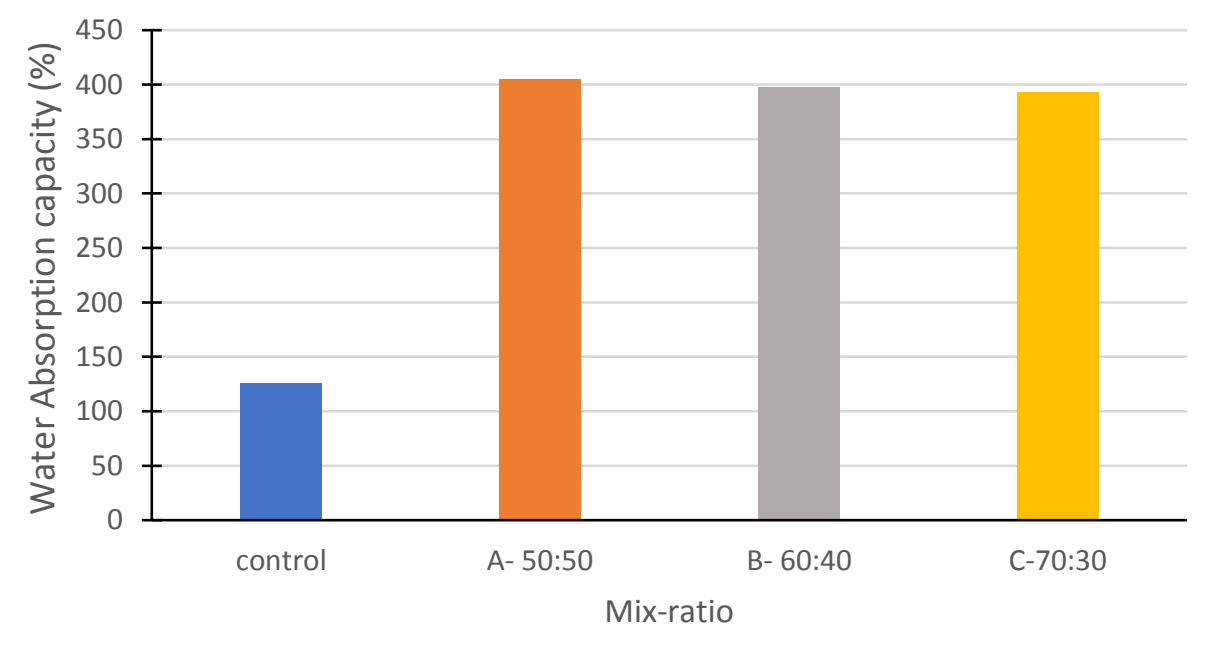

Figure 19: Water absorption capacity for $0.5 \mathrm{~mm}$ particle size at different mix-ratios at different Coir/Bagasse mixratio 


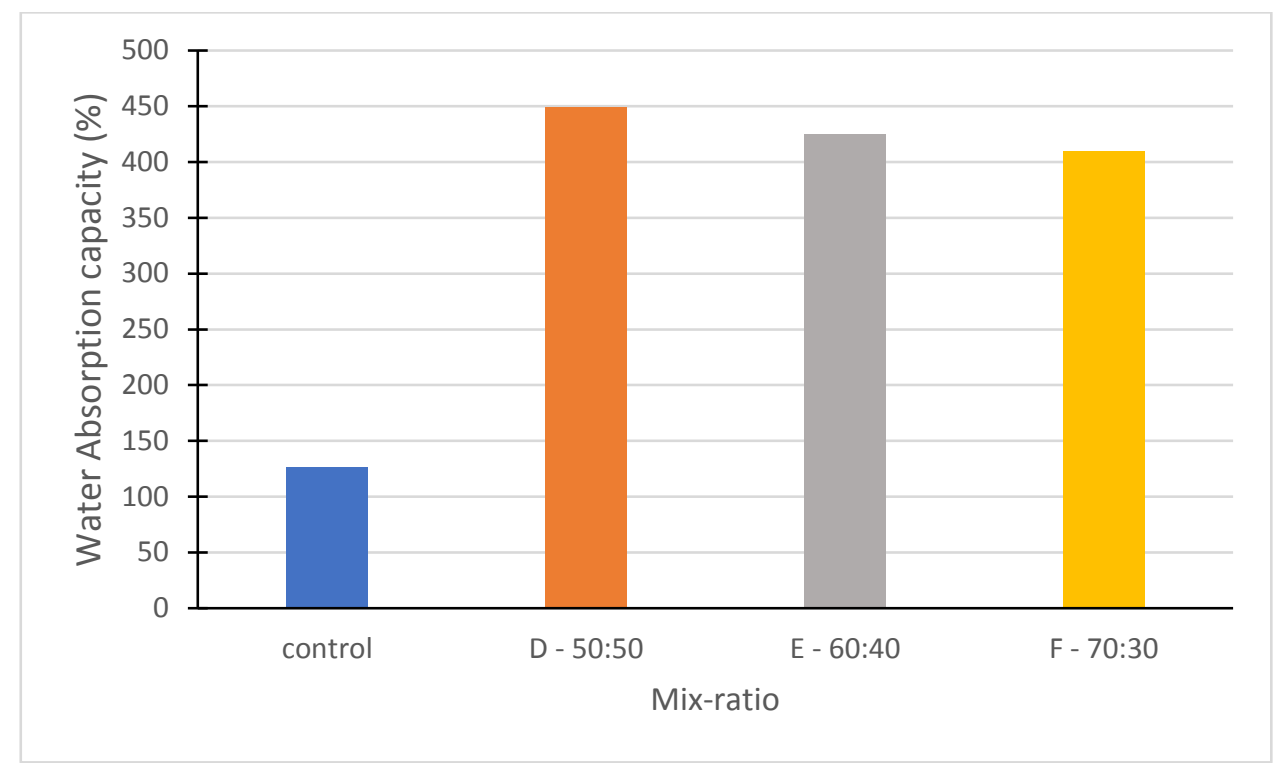

Figure 20: Water Absorption capacity for $1.0 \mathrm{~mm}$ particle size at different Coir/Bagasse mix-ratio

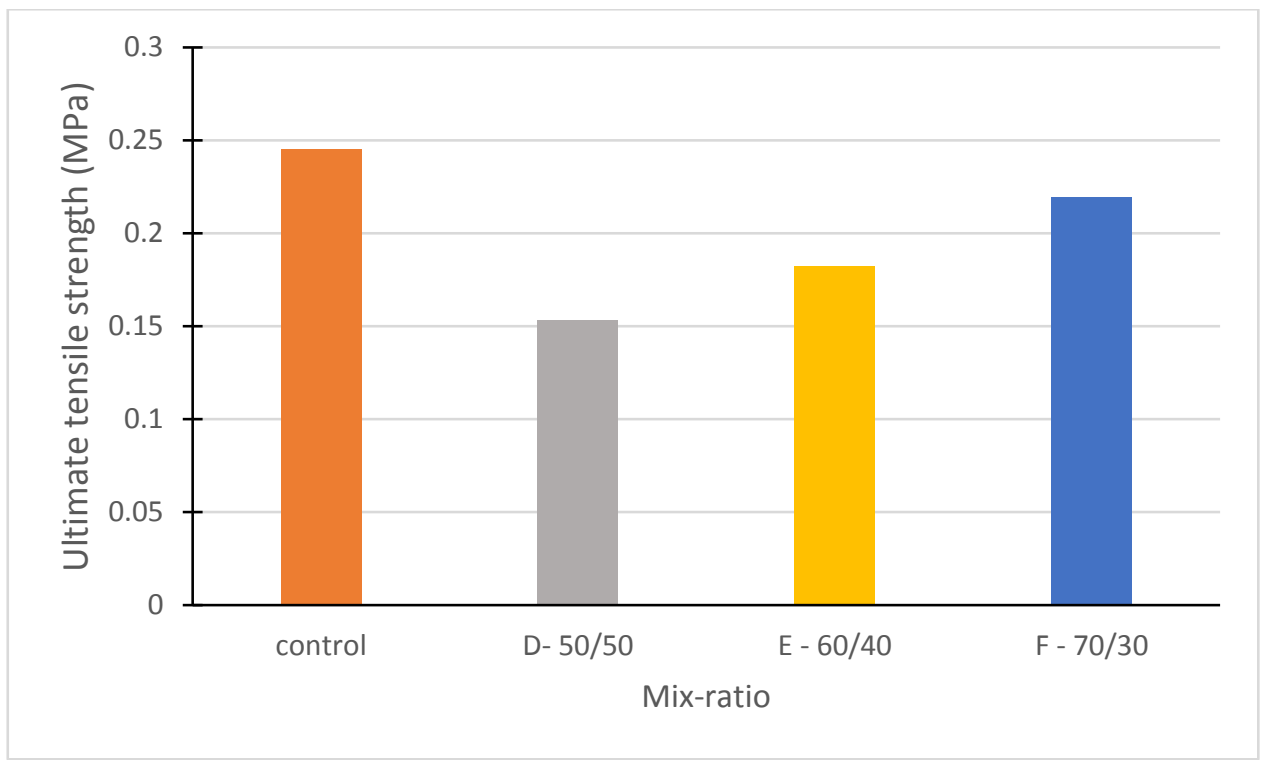

Figure 21: UTS for different mix-ratios for $0.5 \mathrm{~mm}$ particle size at different Coir/Bagasse mix-ratio

\subsection{Ultimate Tensile Strength (UTS)}

Results for the ultimate tensile strength for $0.5 \mathrm{~mm}$ and $1.0 \mathrm{~mm}$ sieve sizes are shown in Figures 21 and 22 . Samples $\mathrm{A}, \mathrm{B}$ and $\mathrm{C}$ (Figure 21) shows a rise in the UTS of the samples and subsequent drop. Sample A has a UTS of 0.22MPa which rose to 0.251 MPa in Sample B and eventually peaked at to 0.259 MPa in Sample C. Samples D, E and F (figure 22) Show a steady continuous rise in the UTS from $0.153 \mathrm{MPa}$ for sample $D$ to $0.182 \mathrm{MPa}$ for sample E and finally peaking at $0.219 \mathrm{MPa}$ for sample $\mathrm{F}$. The steady continuous rise in the UTS for samples $\mathrm{D}, \mathrm{E}$ and $\mathrm{F}$ can be attributed to the increase in the coir percentage from $50 \%$ for sample D to $60 \%$ for sample $E$ and $70 \%$ for sample $F$. This is due to the high lignin content of coir which aids in the binding process of the composite material thereby giving it higher tensile strength. Of the six samples tested sample $C$ had the highest UTS of $0.259 \mathrm{MPa}$ and it can be observed that samples $B$ and $C$ had higher UTS compared to the control sample. Meanwhile the control sample had higher UTS compared to samples $D, E$ and $F$ this is due the sieve size of samples $D, E$ and $F$ which is $1.0 \mathrm{~mm}$ which gives a lower density and decrease in the cohesive bonding force between individual particles. 


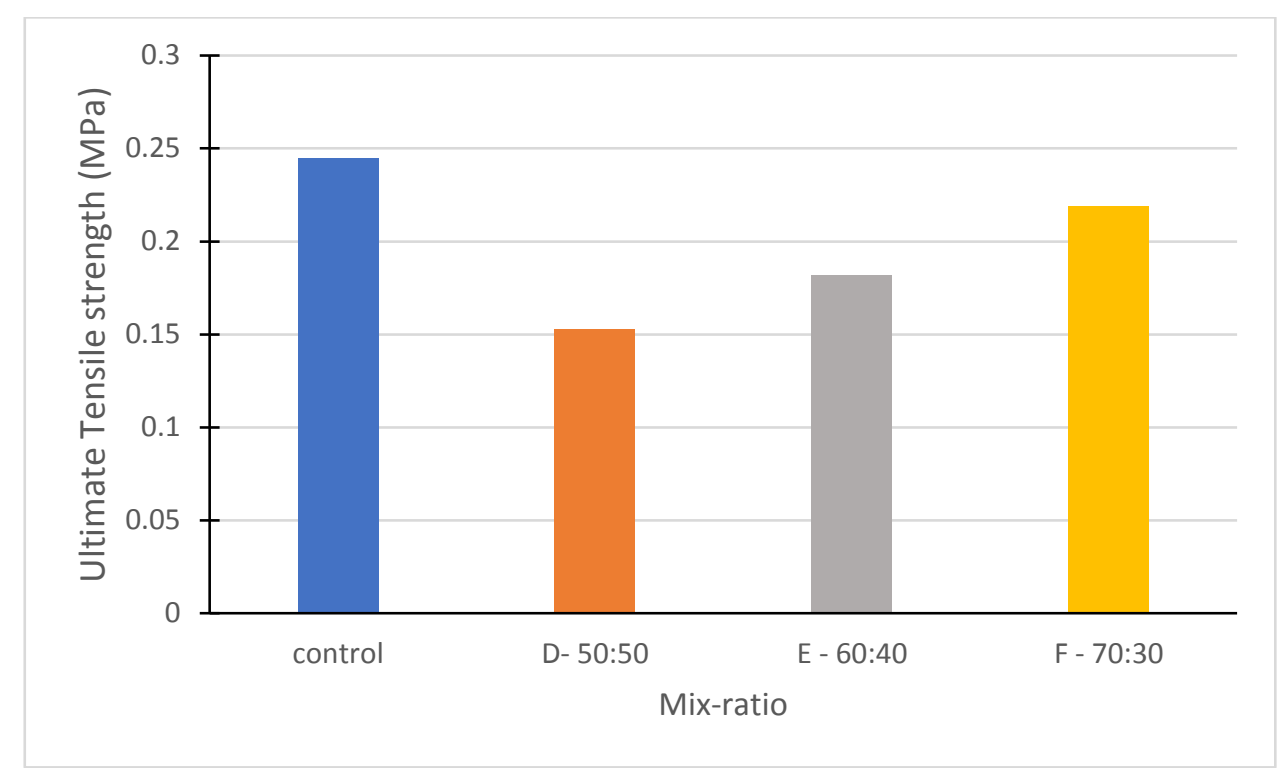

Figure 22: UTS for different mix-ratios for $1.0 \mathrm{~mm}$ particle size at different Coir/Bagasse mix-ratio

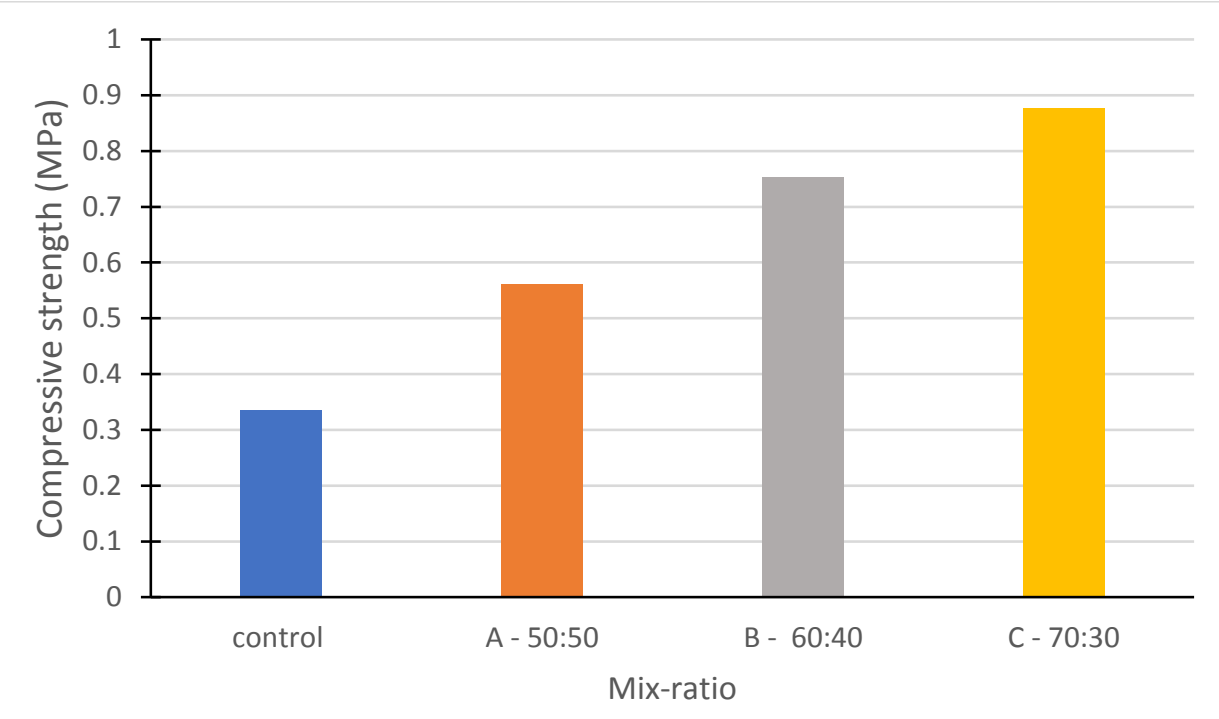

Figure 23: Compressive strength for $0.5 \mathrm{~mm}$ particle size at different mix ratio at different Coir/Bagasse mix-ratio

\subsection{Compressive Strength}

The results for the compressive strength test recorded for $0.5 \mathrm{~mm}$ and $1.0 \mathrm{~mm}$ are shown in Figures 23 and 24 respectively. Samples A, B and $C$ (Figure 23) shows a steady increase in the compressive strength of tested bio composite, sample $A$ had a compressive strength of $0.561 \mathrm{MPa}$ which increased to $0.753 \mathrm{MPa}$ for sample $\mathrm{B}$ and finally peaked at 0.876 for sample $C$ which was significantly higher than the recorded compressive strength of the control sample. The steady increase can be attributed to the small sieve size of $0.5 \mathrm{~mm}$ and increased constituent effect of smaller sieve size and increase in coir content. Samples D, E and F also exhibited similar behaviour as the compressive strength started low at $0.481 \mathrm{MPa}$ for sample $\mathrm{D}$ and rose to $0.522 \mathrm{MPa}$ for sample $\mathrm{E}$ before peaking at $0.583 \mathrm{MPa}$ for sample $\mathrm{F}$. The overall low compressive strength of sample $\mathrm{D}, \mathrm{E}$ and $\mathrm{F}$ as compared to samples $\mathrm{A}, \mathrm{B}$ and $C$, can be attributed to the large sieve size of $1.0 \mathrm{~mm}$ which reduced the density and in turn affected the effective bonding of the bio-composite particles. 


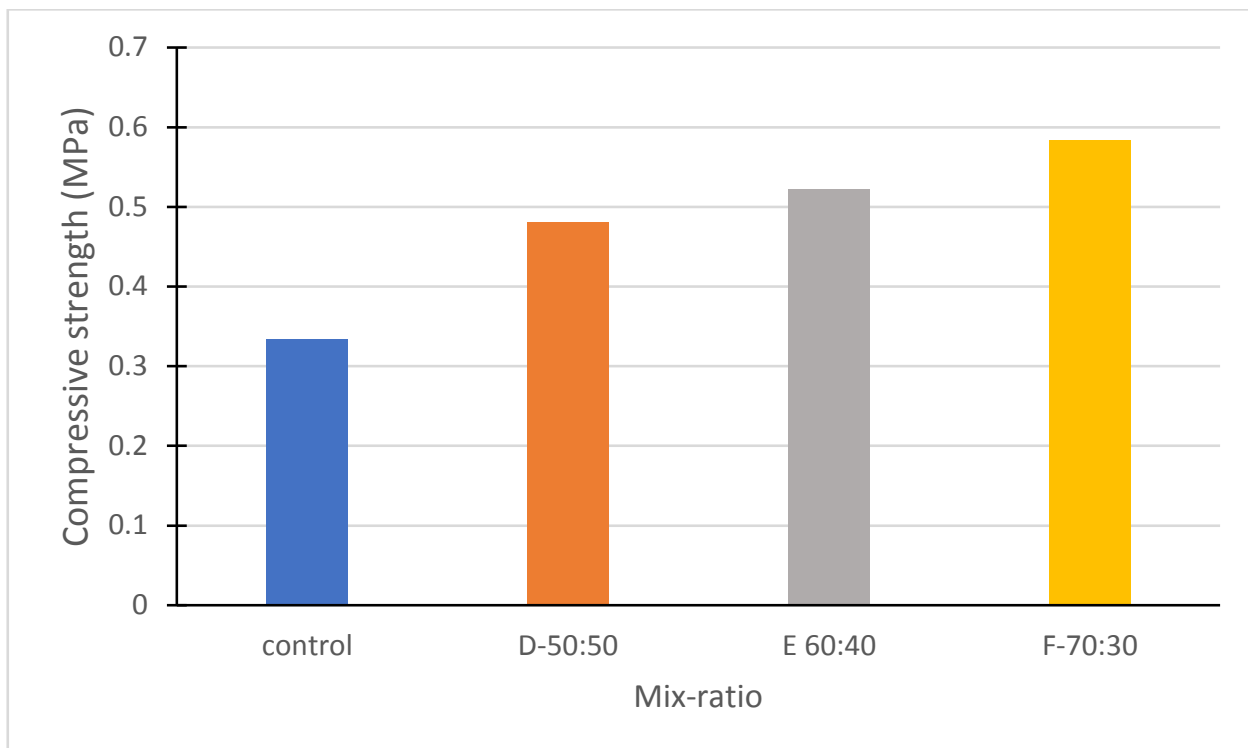

Figure 24: Compressive strength for $1.0 \mathrm{~mm}$ particle size at different Coir/Bagasse mix-ratio

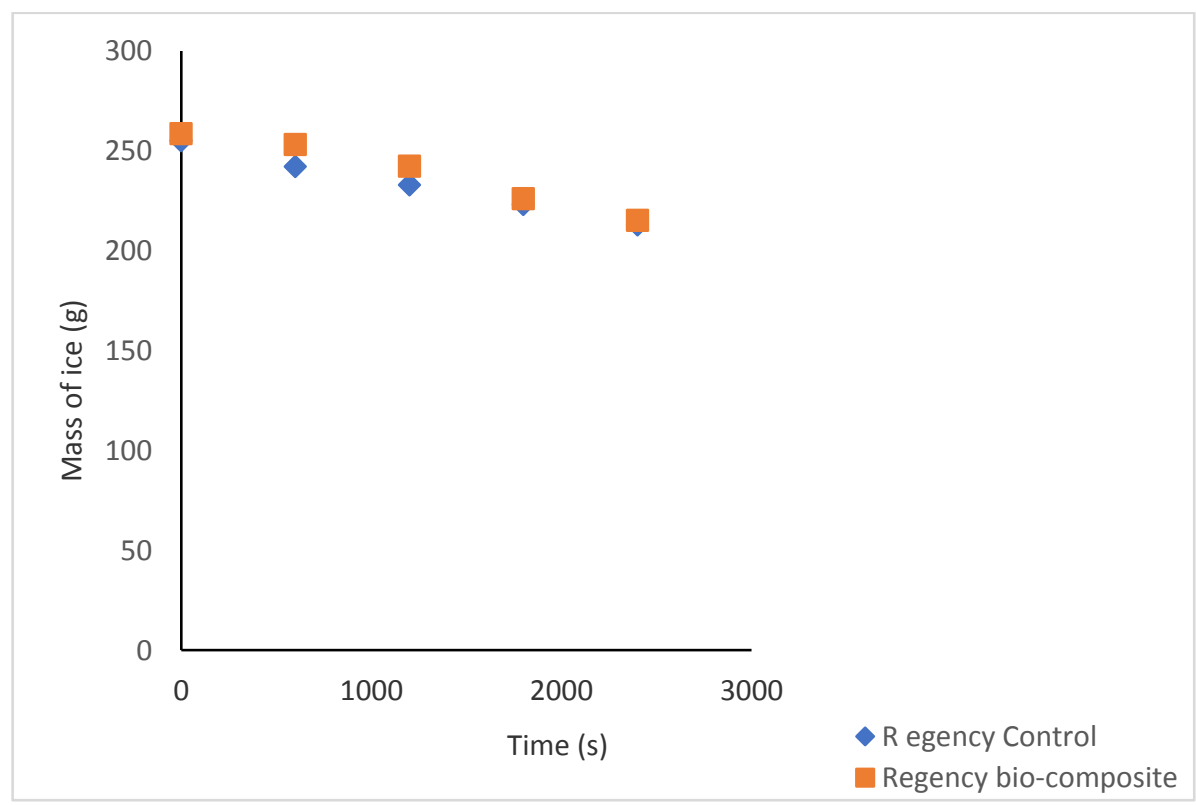

Figure 25: Melt rate (Regency cooler)

\subsection{Performance Evaluation}

Five readings were obtained during the performance evaluation test. The results obtained is shown Figures 25 and 26. The results show a very close proximity of ice mass loss of the Bio-composite material to that of the control food warmer with the Regency food warmer control having a total mass loss of $42.1 \mathrm{~g}$ with a melt rate of $1.05 \mathrm{~g} / \mathrm{min}$ and the Bio-composite lined food warmer having a total mass loss of $43.33 \mathrm{~g}$ with a melt rate of $1.08 \mathrm{~g} / \mathrm{min}$ within the time frame of 40 minutes within which the test was conducted. This represents a difference of $1.23 \mathrm{~g}$ with the control food warmer performing better than the bio-composite lined food warmer, similarly in Figure 4.13 the Thermolineo control food warner has total ice mass loss of $18.51 \mathrm{~g}$ with a melt rate of $0.46 \mathrm{~g} / \mathrm{min}$ and the bio-composite filled Thermolineo food warmer has a total mass loss of $19.86 \mathrm{~g}$ with a melt rate of $0.49 \mathrm{~g} / \mathrm{min}$. This shows a difference of $1.35 \mathrm{~g}$ with the control food ice cooler again performing better than the bio-composite lined cooler. The better performance of the control coolers over the bio composite food warmers can be attributed to lack of proper compaction during the filling process which led to cracks as the bio-composite coolers were being dried, this led to rapid heat transfer which accelerated the melt rate of the ice. 


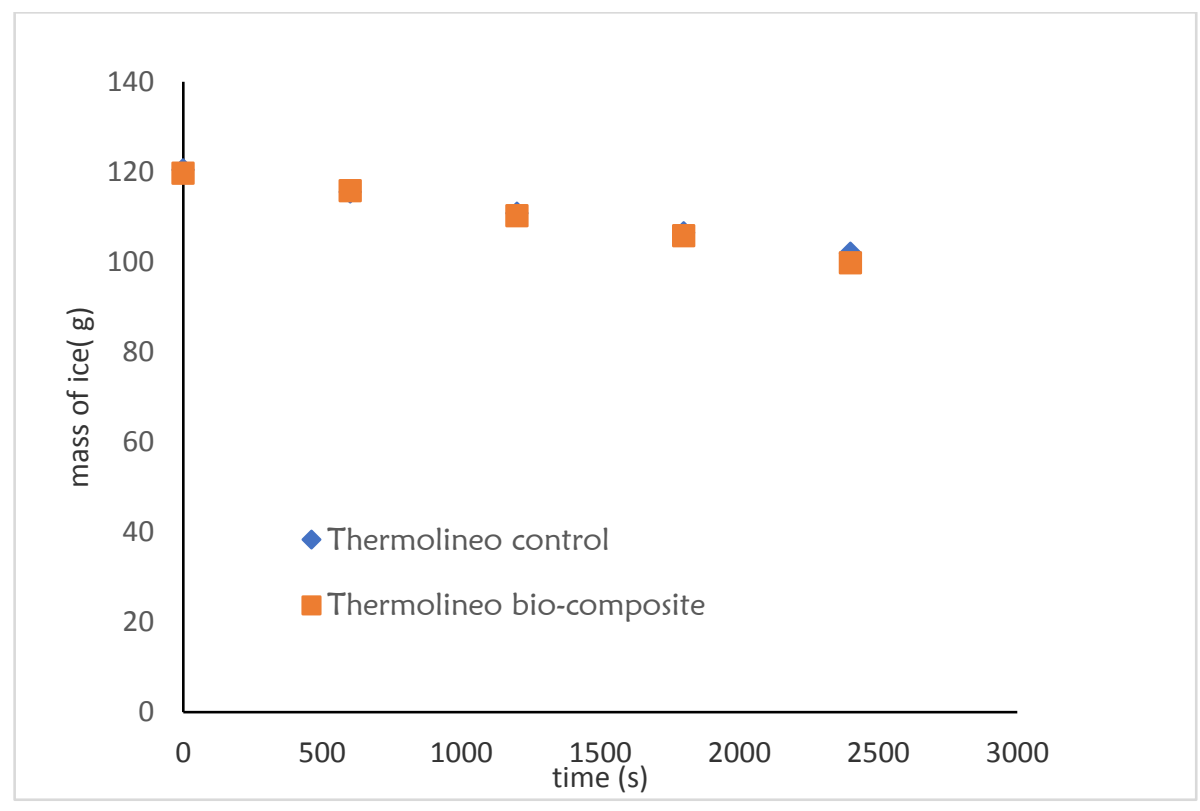

Figure 26: Melt rate (Thermolineo cooler)

\section{CONCLUSIONS}

The conclusions derived from the study can be summarised as thus: Coconut coir and Sugarcane bagasse have lower thermal conductivity and lower thermal diffusivity compared to polyurethane. All samples performed poorly in the water absorption test as compared to the control polyurethane sample. Sieve size and density played important roles in the thermo-physical and mechanical performance of the Bio-composite materials with particle size of $1.0 \mathrm{~mm}$ having higher density as coir percentage increased and performing better than $0.5 \mathrm{~mm}$ particle size in Mechanical and Thermal test , $1.0 \mathrm{~mm}$ particle size sample containing $70 \%$ coir and $30 \%$ bagasse is the most favourable for use as low temperature thermal insulating material to replace the synthetic ones presently being used as it performed favourably across the thermo-physical and mechanical tests that all prepared samples were subjected to Performance evaluation test proved that the combination of coir and bagasse can be used to replace polyurethane insulating materials in low temperature thermal insulation application.

\section{REFERENCES}

1. Dávid Bozsaky, "The historical development of thermal insulation materials," Ŕ Periodica Polytechnica Architecture 41/2 (2010) 49-56 doi: 10.3311/pp.ar.2010-2.02, 2011

2. Krishpersad Manohar "Biodegradable Thermal Insulation for Ice-Coolers," International Journal of Modern Engineering Research 12 (2011) 559-563

3. Agency for Toxic Substances and Disease Registry (ATSDR), "Toxicological profile for Synthetic Vitreous Fibers," (Atlanta: U.S. Department of Health and Human Services, (2004).

4. G. S. Kochhar and K. Manohar, "Effect of moisture on Thermal Conductivity of Fibrous Biological Insulating Materials," Proc. ASHRAE Thermal Performance of the Exterior Envelope of Buildings VI, (Clearwater Beach, Florida, USA, 1995), 33-40.

5. P.F. Infante, et al "Fibrous glass and cancer," American Journal of Industrial Medicine 26, (1994) 559-584

6. J. Pinto et al "Characterization of Corn Cob as a Possible Raw Building Material," Construction Build Mater (2012) 34: 28-33.

7. S. Abdulkareem et al, (2016). "Investigation of Thermal Insulation Properties of Biomass Composites,". International Journal of Technology. 176 (2016) 849-859.

8. Kyauta E.E. Dauda D.M. and Justin E, (2014). Investigation on Thermal Properties of Composite of Rice Husk, Corncob and Baggasse for Building Thermal Insulation. American Journal of Engineering Research (AJER) e-ISSN: 2320-0847 p-ISSN: 2320-0936 Volume-03, Issue-12, pp-34-40

9. Sunil E M, G. Manavendra, (2017). Experimental Investigation on Thermal Properties of Bagasse Fly Ash Reinforced Epoxy Composite. International Research Journal of Engineering and Technology (IRJET) Volume: 04lssue: 09 www.irjet.net.

10. Upadhyay A. HarshalOza J (2015). Investigation on effect of coconut Husk as an insulation on primary energy and $\mathrm{CO} 2$ emissions of residential buildings. International Journal of Advance Engineering and Research Development Volume 2, pp 140-154. 
11. Fong A.L, N A N Khandoker and S Debnath, (2018). Development and Characterization of Sugarcane bagasse fibre and nano-silica reinforced epoxy hybrid composites. IOP Conf. Series: Materials Science and Engineering

12. Y., Mohd Yuhazri, et al "Optimization of Coconut Fibers toward Heat Insulator Applications," Global Engineers \& Technologists Review www.getview.org.

13. Agunsoye, J.O. Aigbodion, V.S (2013). Bagasse filled recycled polyethylene Bio-Composites: Morphological and mechanical properties study.

14. Suresh Babu.R, Karthikeyan.V, VigneshKumar.G (2015), Investigation of Thermal Insulation on Ice Coolers. IOSR Journal of Mechanical and Civil Engineering (IOSR-JMCE) e-ISSN: 2278-1684, Volume 12, Ver. IV (PP 75-79).

15. Ayugi, G E.J.K.B. Banda, F.M. D'Ujanga (2011). Local Thermal Insulating Materials forThermal Energy Storage. Rwanda Journal, Series C, Mathematical Sciences, Engineering and Technology. Volume 23 pp 156-165.

16. Dhivar, P. S, Patil A. S (2017), Thermal Insulation Using Agricultural By-Product:A Review.IOSR Journal of Mechanical and Civil Engineering (IOSR-JMCE) PP. 53-61www.iosrjournals.org.

17. EeydzahAminudin, N, Khalid A., Nor Azman, K, MohdFadhilMd D, Rozana Z, And NurAzmira Z, (2017). Utilization of Baggase Waste Based Materials as Improvement for Thermal Insulation of Cement Brick. MATEC 